\title{
Lunar Surface Mechanical Properties-Surveyor 1
}

\author{
Elmer M. Christensen, ${ }^{1}$ S. A. Batterson, ${ }^{2}$ H. E. Benson, ${ }^{3}$ \\ Claude E. Chandler, ${ }^{1}$ R. H. Jones, ${ }^{4}$ Ronald F. Scott, ${ }^{,}$ \\ E. N. Shipley, ${ }^{6}$ Frank B. Sperring, ${ }^{1}$ and G. H. Sutton ${ }^{7}$
}

\begin{abstract}
Engineering telemetry data and lunar surface photographs by Surveyor 1 have been evaluated for information on the mechanical properties of the lunar surface material at the Surveyor 1 landing site. Based primarily on photographic evidence, estimates of soil density, cohesion, and other soil characteristics are presented. Also, the mechanisms in which the lunar material is believed to have failed under the footpad impacts are discussed. Because dynamic soil reactions cannot be interpreted directly from the available data, a comparative study using computer-simulated landings was initiated. Preliminary results of this study, which is still in progress, are presented.
\end{abstract}

\section{Obgervations and Explanations}

The interpretation of the lunar surface properties discussed here is based on (1) television photographs showing the lunar surface areas disturbed by the footpads and the framemounted crushable blocks, (2) histories of axial loads in the shock absorber on each of the three legs during landing (Figure 1), and (3) other engineering telemetry data pertinent to landing dynamics. The dimensions of the landing gear assembly are shown in Figure 2, and the motion of each leg set during landing is shown schematically in Figure 3. The spacecraft landed with a vertical velocity of approximately $3.5 \mathrm{~m} / \mathrm{sec}$ $(11.6 \mathrm{ft} / \mathrm{sec})$ and a horizontal velocity of approximately $0.3 \mathrm{~m} / \mathrm{sec}(1 \mathrm{ft} / \mathrm{sec})$. At touchdown, the angle between the plane of the three footpads and the local lunar surface was approximately $1.2^{\circ}$. At rest on the surface, the spacecraft frame is now estimated to be parallel to the local lunar surface within $1^{\circ}$.

Figure 4 shows the time records of the axial load, as measured by a strain gage, on each

1 Jet Propulsion Laboratory, California Institute of Technology, Pasadena.

2 Dynamic Loads Division, NASA Langley Research Center, Hampton, Virginia.

${ }^{3}$ National Aeronautics and Space Administration, Manned Spacecraft Center, Houston, Texas.

4 Hughes Aircraft Company, El Segundo, California.

s California Institute of Technology, Pasadena.

- Bellcomm, Inc., Washington, D. C.

7 Hawaii Institute of Geophysics, University of Hawaii, Honolulu. shock absorber. (Computer-simulated landing data for landing on a hard surface are presented in Figure 5.) It can be seen that surface contact for all three footpads was almost simultaneous, indicating that the spacecraft mast (Figure 1) at touchdown was approximately normal to the surface. The footpads impacted at intervals of approximately 0.01 sec. Footpad 2 touched first, followed by footpad 1 and then footpad 3.

The record also shows that, approximately 500 msec after initial touchdown, the spacecraft rebounded. A second impact is registered approximately $1.1 \mathrm{sec}$ after the first one. This timing of events indicates that the footpads

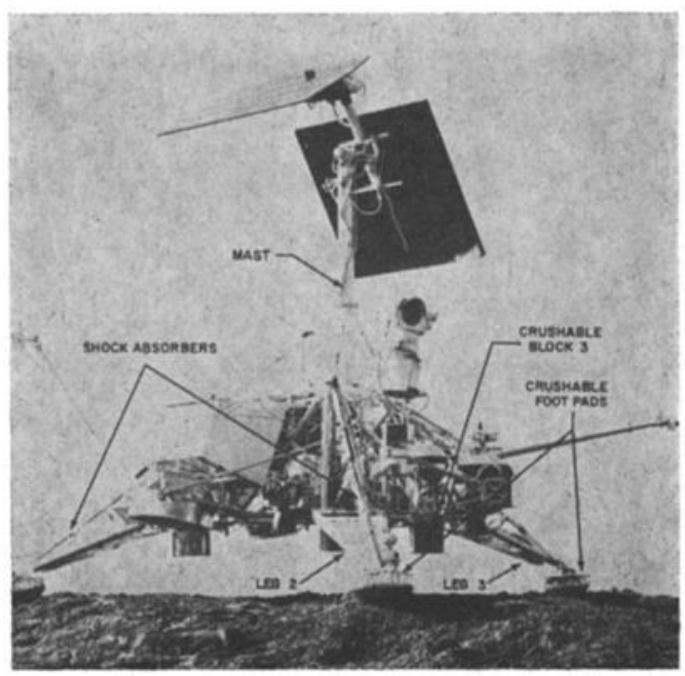

Fig. 1. Surveyor spacecraft. 


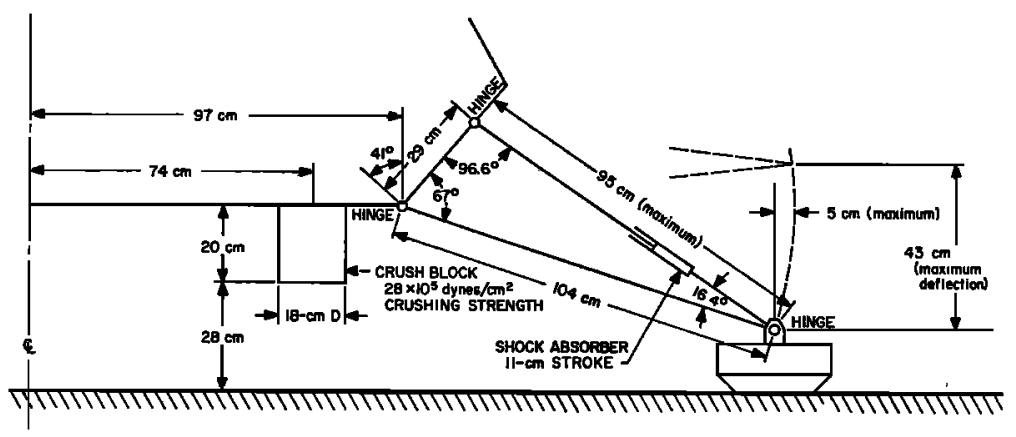

FOOTPAD DETAIL

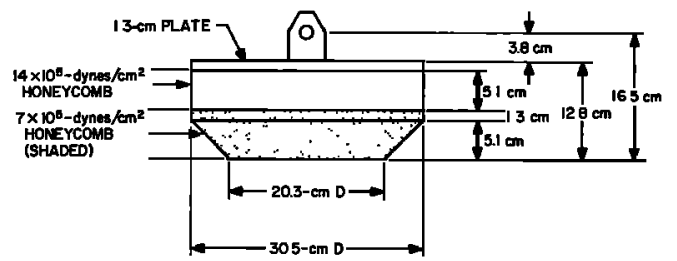

Fig. 2. Dimensions of landing gear assembly.

(a)

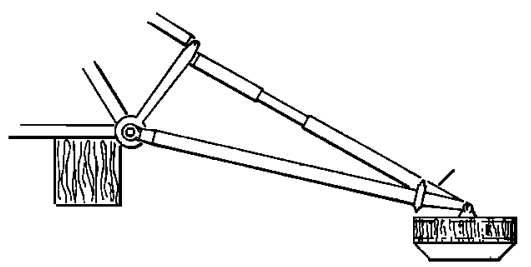

(b)

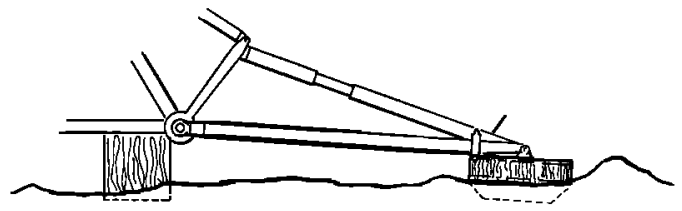

(c)

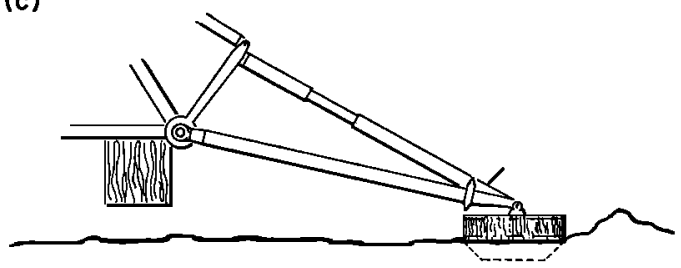

Fig. 3. Surveyor landing leg assembly, showing articulation in events during landing. Assembly is shown fully extended in (a); during landing, the shock absorber compresses and the footpad moves up and away from the spaceframe, as shown in (b); assembly is shown reextended after landing in (c). cleared the lunar surface by about $6 \mathrm{~cm}(2.5$ inches) during the rebound phase. The second impact developed maximum loads equal to approximately one-quarter of the maximum loads developed during initial impact. The maximum vertical load applied to a footpad by the lunar surface material during initial impact was approximately 1900 to 2200 newtons (450 to 500 lb), which was determined by comparing analytical landing simulations with Surveyor 1 telemetry data. Conversion of this load into a dynamic pressure applied to the surface depends on the footpad area in contact with the soil at the instant the load is measured. Since the lower portion of the footpad is a truncated cone (Figure 2), this contact area depends primarily on the penetration depth; thus, a maximum loading of between $4.2 \times 10^{5}$ and $6.9 \times 10^{5}$ dynes $/ \mathrm{cm}^{2}$ ( 6 and $10 \mathrm{psi}$ ) was applied to the surface during the dynamic stages of the impact. The static load required to support the spacecraft on the three landing pads is approximately $3 \times 10^{4}$ dynes $/ \mathrm{cm}^{2}(0.5 \mathrm{psi})$. The earth weight of the spacecraft at the time of landing was 2863 newtons (643 lb); its mass was 291.8 $\mathrm{kg}$ (20.0 slugs).

Oscillations of the forces in all the shock absorbers are seen to follow the second impact (Figure 4) with maximum peak-to-peak ampli- 

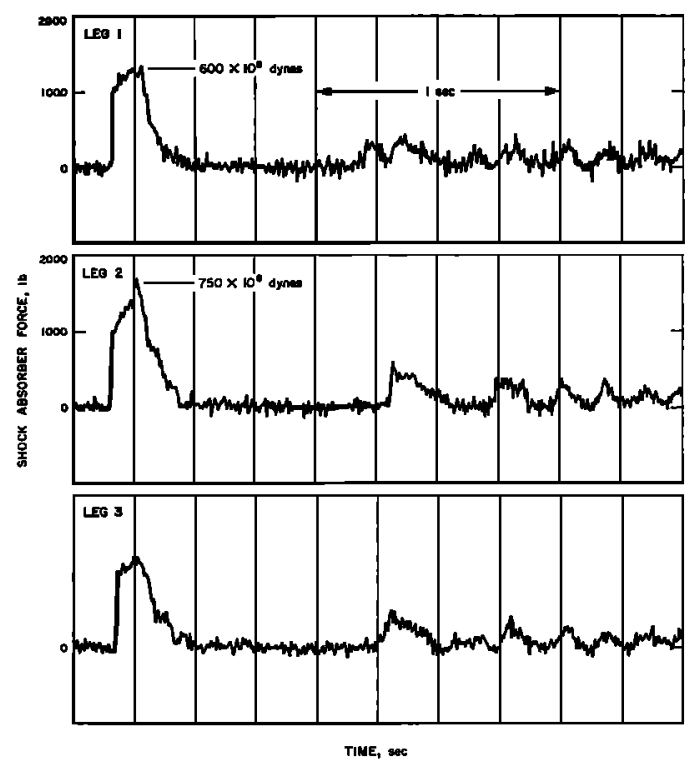

Fig. 4. Axial shock absorber strain gage data. (Maximum force developed by shock absorber 3 is not shown because of uncertainties in no. 3 strain gage calibration.)

tude of several hundred pounds and a frequency near $7 \mathrm{cps}$. The oscillations are in phase and of about equal amplitude, thus indicating a rectilinear vertical motion of spacecraft center of gravity. (Maximum amplitude displacement of spacecraft center of gravity is approximately $0.2 \mathrm{~cm}$, or $0.08 \mathrm{in}$., assuming a linear system.) The frequency of the oscillations is related to the elasticity of the spacecraft structure and the lunar surface material. Consequently, for frequencies appreciably lower than $7 \mathrm{cps}$, the spacecraft is well coupled to the moon. This observation is important for a lunar seismograph experiment, in which the seismographic sensor is mounted rigidly in the spacecraft frame, since it permits one to expect reliable recording of seismographic signals with frequencies below $7 \mathrm{cps}$. Higher-frequency signals would be attenuated, with the possible exception of certain discrete resonant frequencies.

The appearance of the disturbed lunar surface near footpad 3 (Figure 6) and footpad 2 (Figure 7) indicates a similar behavior of the material displaced by the two footpads. They appear to have landed in a granular material, to have extended laterally approximately $5 \mathrm{~cm}$ (2 in.) during impact (Figure 3), forcing the surface material away, and then to have drawn back to their final position. Footpad 1 is not visible to the television camera.

At footpads 2 and 3, there is a throwout pattern over the surface (Figures 6 and 7), including rays of apparently fine-grained material, to a distance of 0.5 to 0.8 meter (1.5 to $2.5 \mathrm{ft}$ ) from the edge of the footpad. Nearer the footpad, the lunar material was displaced to form a raised rim. The sides of the depression and the rim have a chunky or blocky appearance (Figures 7 and 8 ), the blocks or clumps of material are irregular, have a range of sizes, and appear to consist of aggregates of finegrained material rather than of individual stones or pebbles. The basic grain size seems to be below the limit of resolution of the narrow-angle pictures in 600-line mode, about 0.5 $\mathrm{mm}$ (0.02 in.) at the distance of footpad 2 (approximately 2 meters, or $7 \mathrm{ft}$ ). Footpad 2 movements during landing caused some small deformations of the surface adjacent to the footpad on the side nearest the camera (Figure 9). The deformations resulted in an irregular pattern of cracks or fissures at the surface of the material.

Late in the second lunar day, a picture of footpad 2 (Figure 10) was obtained. The top of the footpad has the texture of a layer of fine lunar material; however, because none of the earlier pictures indicate such a layer, and because there is no known event that could have deposited it, the texture is possibly the result of unevenness in the paint, accentuated by the low sun angle of $6^{\circ}$ that prevailed at the time this picture was taken.

The maximum depth of footpad penetration can be determined only approximately, particularly since it is not known whether the final position represents the maximum penetration.

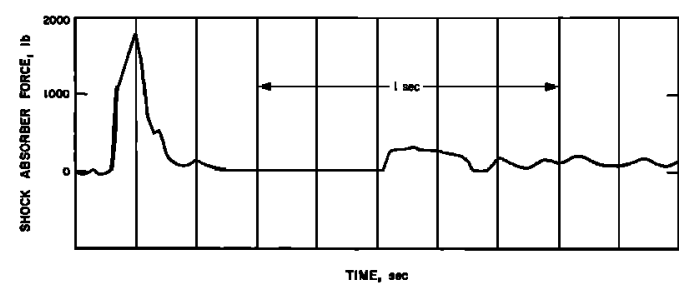

Fig. 5. Computer-simulated axial shock absorber strain gage data for landing on a hard surface. 


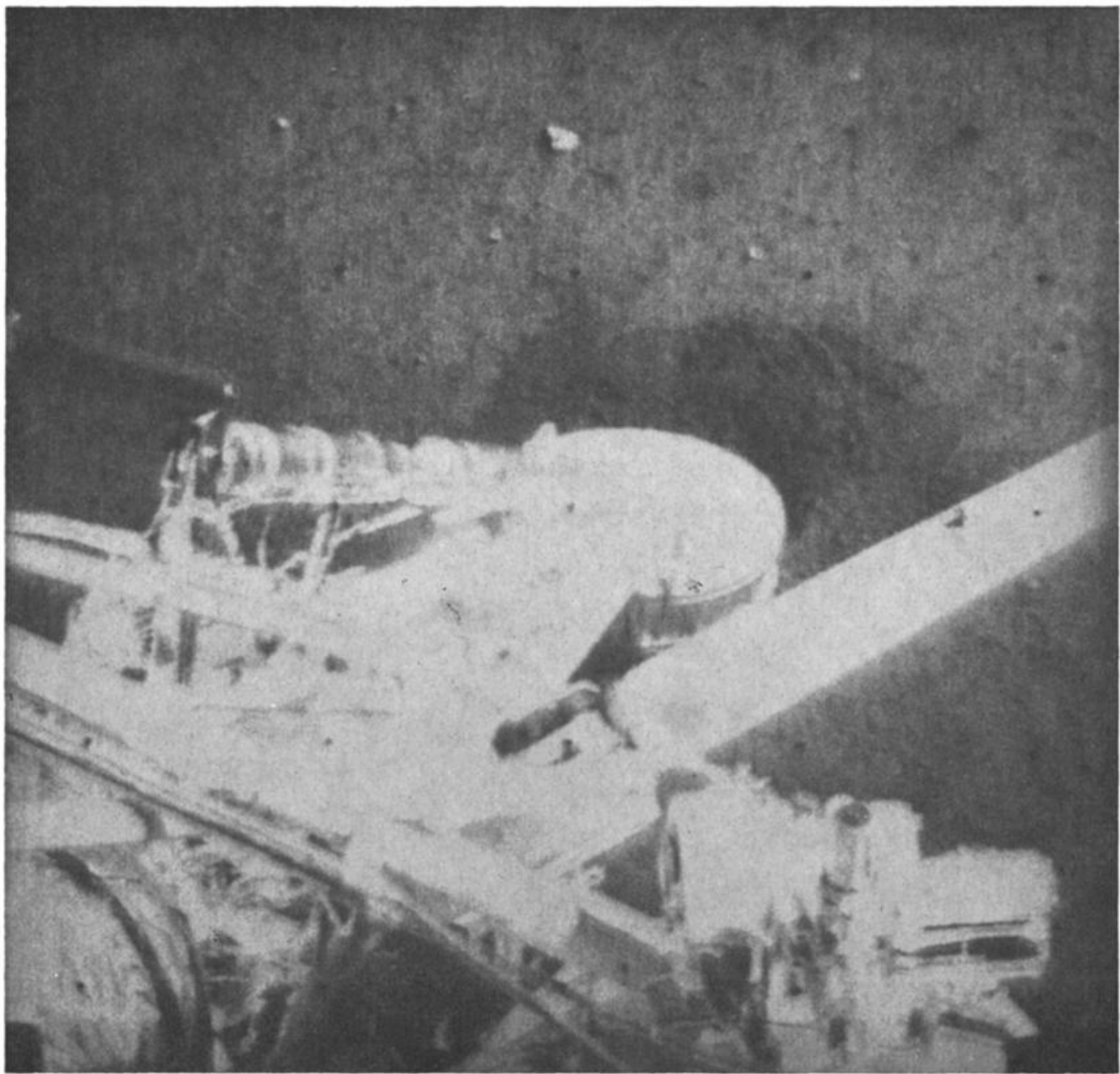

Fig. 6. Wide-angle picture of footpad 3. Note similarity of throwout material to material shown in Figure 7. (A better reproduction can be found at the back of the Journal. See Plate 15.)

The penetration of the pads in their final position has been estimated from shadow measurements and observations of numerous photographs. Assuming that there is no pad crushing, the best estimate is that the bottom surface of pad 2 is 4 to $8 \mathrm{~cm}$ (1.5 to 3 in.) below the adjacent undisturbed surface (Figures 8 and 11); the bottom surface of footpad 3 penetrated at least $3 \mathrm{~cm}$ (1.25 in.). By using morning and afternoon shadow measurements, it has been determined that the top of the footpad 2 is $9 \mathrm{~cm}$ (3.5 in.) above the lunar surface to the west of the footpad and $5 \mathrm{~cm}$
( 2 in.) ahove the lunar surface to the east of the pad. These numbers establish the penetration given above, based on the height of the uncrushed footpad, which is approximately $12.5 \mathrm{~cm}$ (5 in.). The crest of the ridge of disturbed material near footpad 2 is approximately $15 \mathrm{~cm}$ ( 6 in.) beyond the far side of the footpad.

Studies of the low-velocity impact of flatbased objects into cohesionless soils indicate that the crest of the crater formed by the impact occurs less than 1 diameter beyond the edge of the projectile (R. F. Scott, unpublished 
work in the Division of Engineering and Applied Science, California Institute of Technology, 1966). As the projectile penetrates the soil, some of the material formerly occupying the crater cavity is thrown outward as an overlay, and some material is pushed in both a downward and a lateral direction to form the crater rim. The appearance of the soil and measurements made from the pictures of the Surveyor 1 footpads are compatible with these observations. It can be concluded, therefore, that some of the lunar surface soil was thrown out and some was displaced laterally by the impact of the footpad; however, it is not possible to estimate to what extent the material was compressed because the footpads obscure parts of the areas where the material was pushed or thrown.

Pictures of a depression in the lunar surface under crushable block assembly 3 (Figures 12

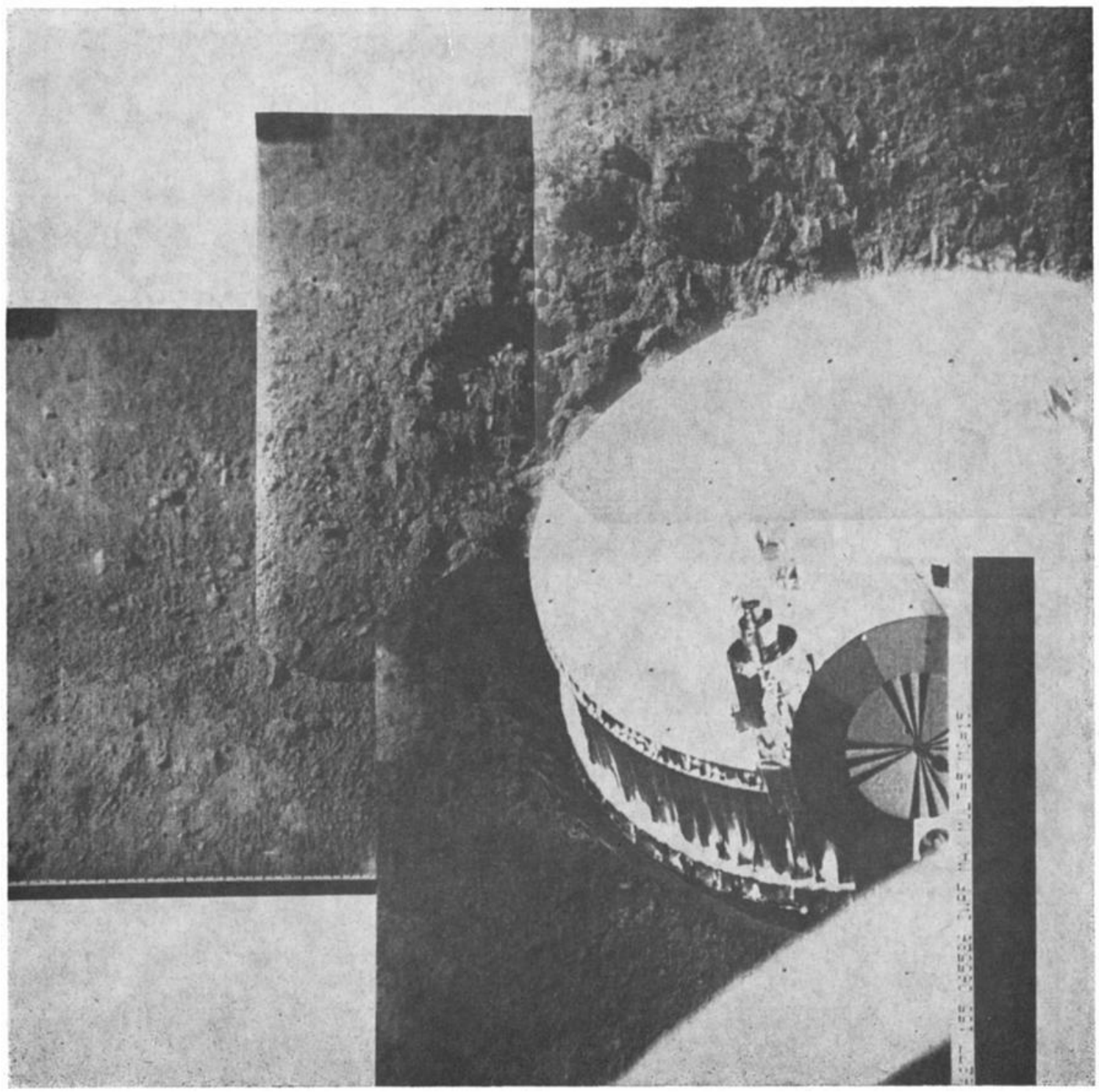

Fig. 7. Mosaic of computer-processed narrow-angle pictures of footpad 2 area taken on June 4, 1966. Sun angle is $54^{\circ}$. (A better reproduction can be found at the back of the Journal. See Plate 16.) 


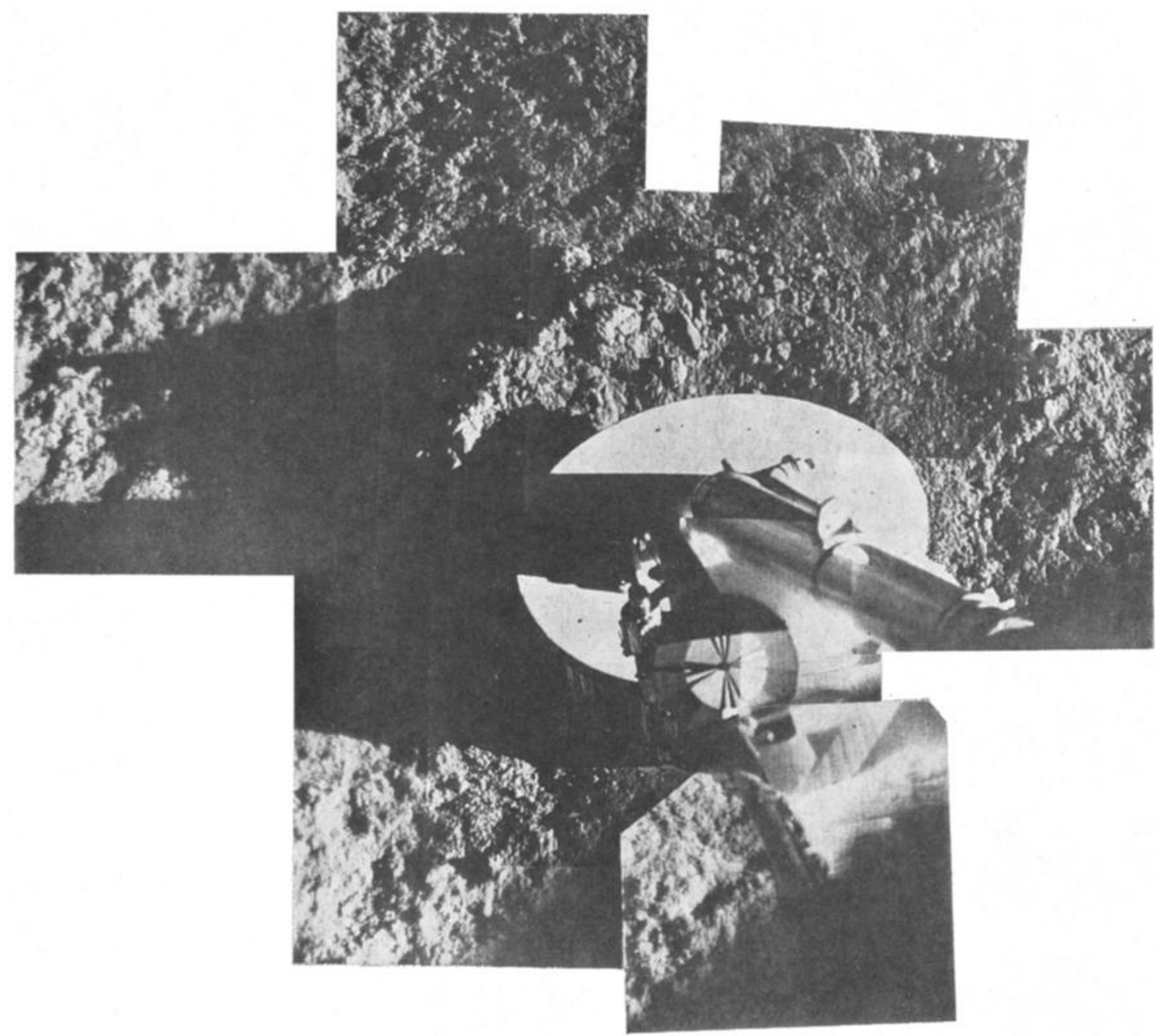

Fig. 8. Mosaic of computer-processed narrow-angle pictures of footpad 2 area taken on June 13, 1966. Sun angle is $10^{\circ}$. Note that four frames are not computer-processed. (A better reproduction can be found at the back of the Journal. See Plate 17.)

and 13) indicate that it also made contact with the lunar surface. It has not been possible to identify any lunar surface depression under crushable block assembly 1 because of spacecraft shadows in that area. The area beneath crushable block assembly 2 and the crushable blocks themselves cannot be seen with the Surveyor television camera. The symmetry of the impact and the general local flatness of the lunar surface, however, lead to the conclusion that all three of the crushable blocks made contact with the lunar surface.

Measurements of shadows in the block 3 impact area indicate a depression depth of ap- proximately $2 \mathrm{~cm}$ (0.75 in.). However, the depression, or imprint (Figures 12 and 13), was not made by block 3 itself. The sharp outline of the imprint was made by the thermal insulator that partly surrounds the block (Figure 14). It appears that, as the block penetrated into the soil, some material was pushed into the annular space between the block and the insulator. Then, as the spacecraft rose, this material fell back, partly into the depression. This explains the fact that the lunar material in the imprint does not have a crushed appearance and that the material was not sprayed out around the imprint. Factors that can be 
postulated from the above statements and from the study of the pictures are:

1. Block assembly 3 penetrated more than $2 \mathrm{~cm}(0.75 \mathrm{in}$.).

2. Lunar material is compressible to some extent because an appreciable depression was formed with only a slight visible raising of adjacent material. (This conclusion is tentative because of the small percentage of depressed area and of the visible surrounding region.)

3. Lunar material has cohesion; i.e., the edge remains standing at an angle of at least $58^{\circ}$. (In Figures 12 and 13, the edge appears vertical; however, the camera line of sight to block 3 is $58^{\circ}$ above the horizon.)

To determine whether any surface erosion could be caused, the attitude-control jet on leg 2 (Figures 3 and 7) was operated after landing. The jet used cold nitrogen gas to produce a thrust of 0.3 newton $(0.06 \mathrm{lb})$. It was located approximately $12 \mathrm{~cm}$ (5 in.) from, and at an angle of $72^{\circ}$ to, the surface. Pictures were taken before, during, and after the firings, which consisted of short pulses repeated for

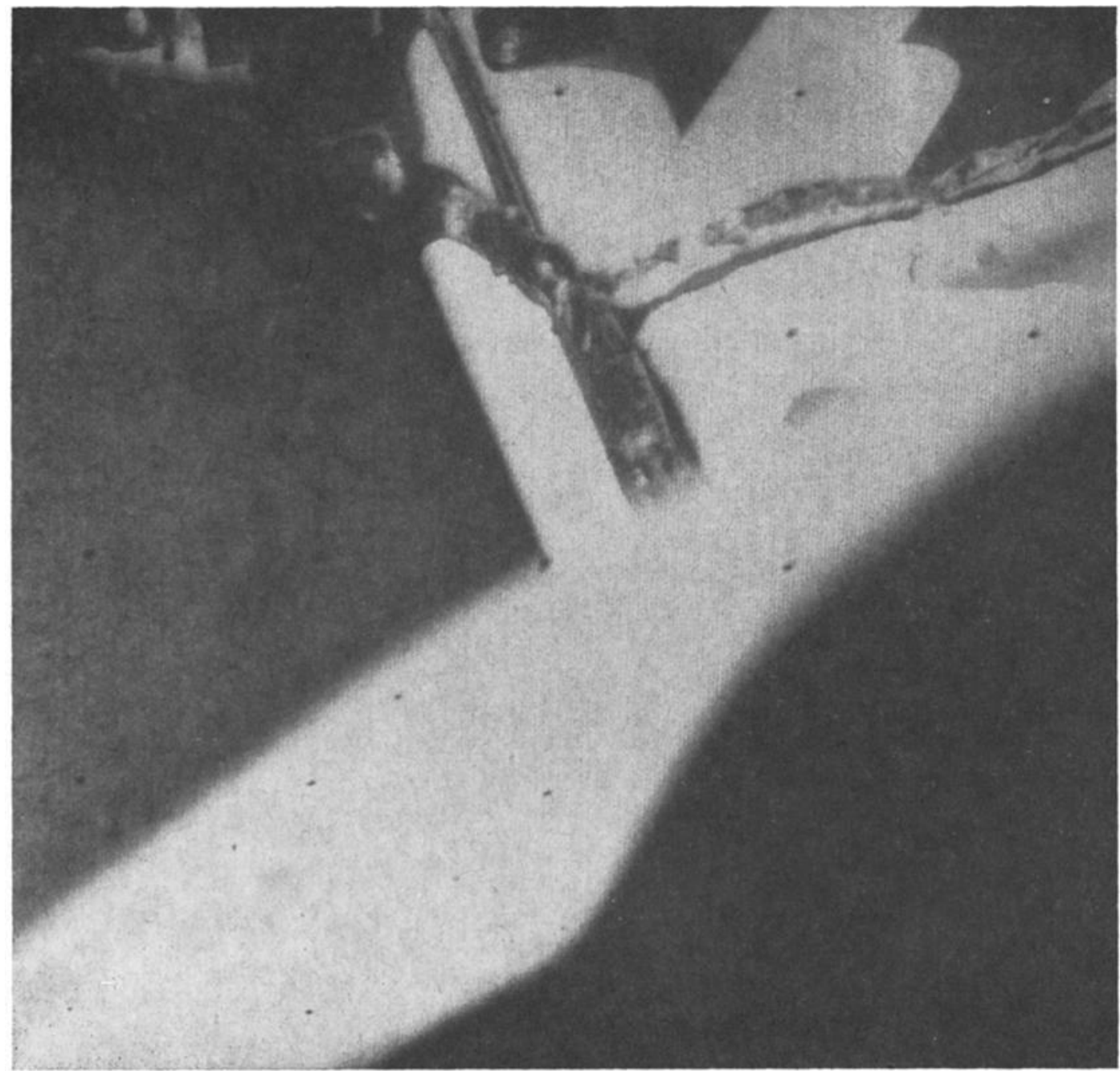

Fig. 9. Narrow-angle picture of disturbed lunar surface material near footpad 2. Disturbed lunar material is in the approximate area in which the exhaust of the attitude control jet impinged on the surface. (A better reproduction can be found at the back of the Journal. See Plate 18.) 


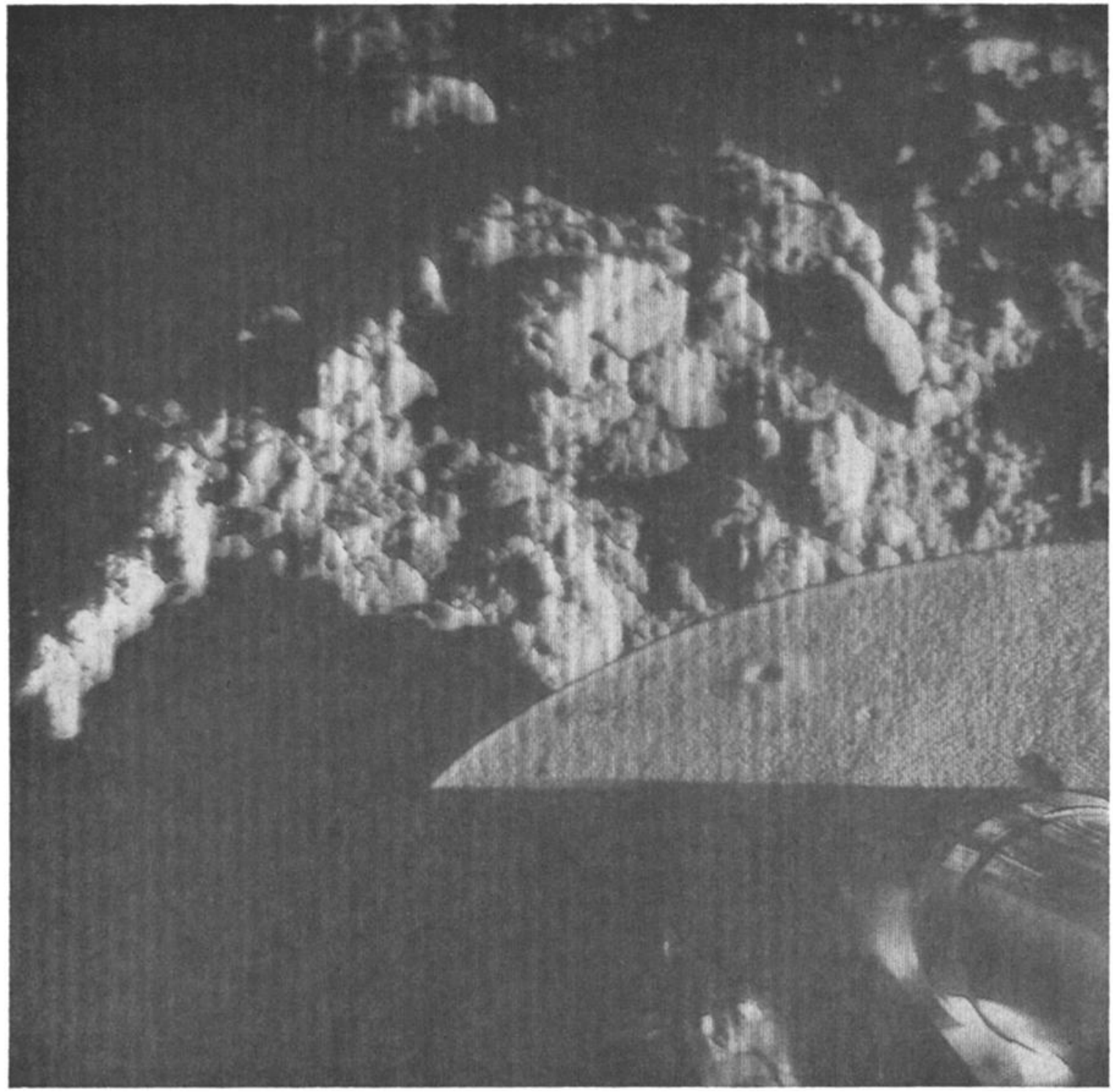

Fig. 10. Narrow-angle picture of footpad 2. Sun angle is $6^{\circ}$ above horizon; texture on pad top is unexplained. (A better reproduction can be found at the back of the Journal. See Plate 19.)

periods up to $12 \mathrm{sec}$. The pulse duration was 20 msec with a 30 -msec pause between pulses. No soil disturbance has been observed except for a single anomaly. Pictures taken after the firing indicate the existence of a slight dimple crater in the surface in the approximate area in which the gas jet struck the lunar material (Figure 9); however, the pictures taken before the firing are inadequate for determining whether the feature was present prior to the firing.

No change in the spacecraft position or attitude has been detected after the landing transient subsided. Within a few minutes after touchdown, locking devices were actuated to prevent any further motion of the shock absorbers, which might result from hydraulic fluid leakage. Examination of late afternoon 
Fig. 11. Narrow-angle picture of footpad 3. Sun angle is $25^{\circ}$; camera angle from which this picture was taken enabled the surface in foreground of footpad to be seen. (A better reproduction can be found at the back of the Journal. See Plate 20.)

photographs of the footpad 2 and 3 areas taken on the first and second lunar day revealed no detectable movements of (1) any lunar particles down to the limit of photographic resolution or (2) the relative position of the pads to the lunar surface. Similarly, no change in the lunar material has been observed around the block 3 imprint.

\section{Analysis of Touchdown Dynamics}

The spacecraft's final descent velocities and attitudes were determined by correlating the velocity data from the radar altimeter and Doppler velocity sensor, the three gyro-angular rates about the spacecraft axis (as indicated by the gyroscopes), and the precise timing of 


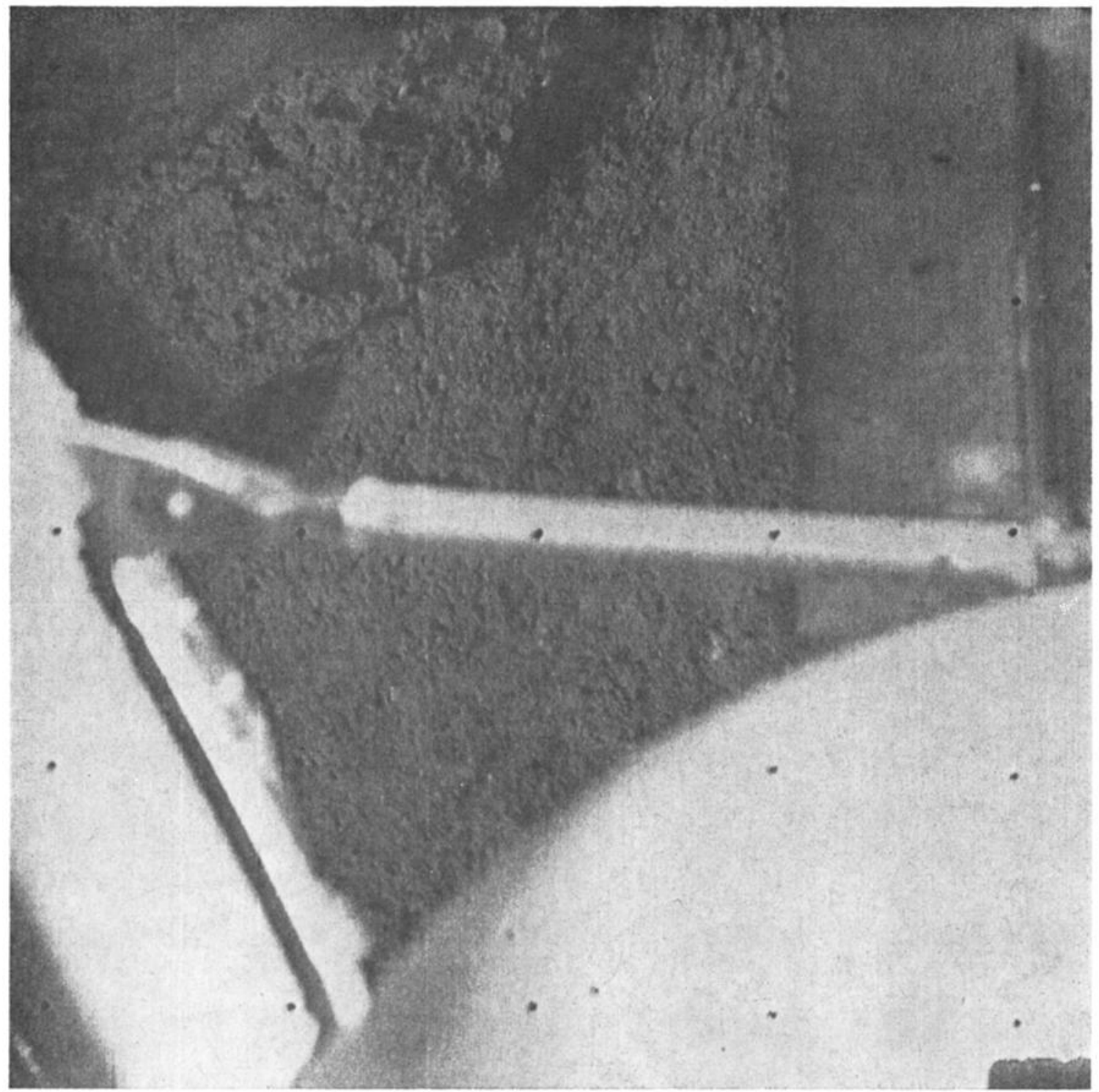

Fig. 12. Computer-processed picture of surface depression made by crushable block assembly 3. Note the lunar surface depression in upper left-hand corner; part of the propellant tank obscures the imprint in the extreme left-hand corner. Sun angle is $41^{\circ}$ and from the right of the picture. (A better reproduction can be found at the back of the Journal. See Plate 21.)

the final descent and touchdown events. (The performance of Surveyor 1 is detailed in Surveyor 1 Mission Report [1966].) By use of lunar gravity free-fall equations from vernier engine cutoff to touchdown, the vertical landing velocity was calculated. The spacecraft gyro data show that no significant angular motions occurred between vernier engine cutoff and the spacecraft's settling onto the surface. By using the above velocity and spacecraft performance data, analytical simulations of the landing dynamics have been performed. These analyses are based on extensive computer landing simulation studies, which were confirmed by full-size vehicle drop tests prior to the Surveyor 1 mission [Sperling and Garba, 1966]. 


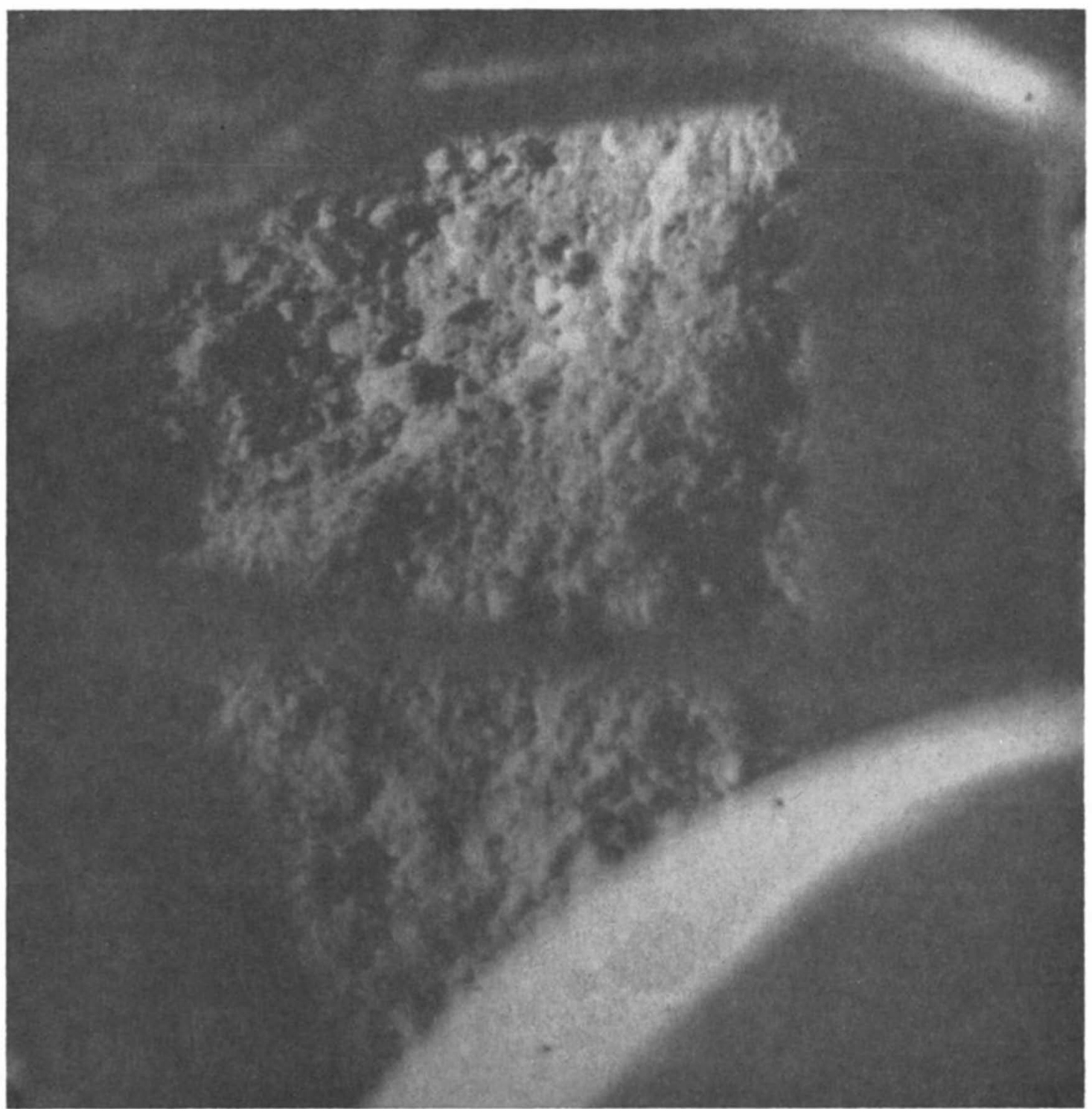

Fig. 13. Block assembly 3 imprint taken late on the second lunar day. Sun angle is $22^{\circ}$ and from the left of the picture. No noticeable change in the disturbed material has been observed during a time period greater than 5 weeks. (A better reproduction can be found at the back of the Journal. See Plate 22.)

Simulated-landing computer runs were performed assuming a rigid lunar surface, as well as a 'soft' surface, in which the vertical ground force acting on each footpad is represented by an equation of the following form:

$$
F_{v}=C_{1}+C_{2} Z+C_{3} \dot{Z}^{2}
$$

where $\mathbf{Z}$ represents the penetration into the lunar soil material, $\dot{Z}$ is the penetration velocity, and
$C_{1}, C_{2}$, and $C_{2}$ are characteristic lunar surface coefficients (i.e., $C_{1}$ is the force statically exerted by the topmost layer of lunar surface material, $C_{3}$ is the increase in static bearing strength with penetration, and $C_{3}$ represents dynamic soil effects). Other soil force equations are under investigation for the determination of potential soft surfaces that would simulate the Surveyor 1 results. 
There are various soil types that could have produced the Surveyor 1 strain gage traces and be consistent with the observed penetrations. For all soil types, however, the static bearing strength on the top surface layer must be in the range of 0 to $6.9 \times 10^{5}$ dynes $/ \mathrm{cm}^{2}$ ( 0 to $10 \mathrm{psi}$ ). For higher values, very little, if any, penetration would have occurred because the maximum dynamic load imposed on the surface by the footpads was not higher than $6.9 \times 10^{5}$ dynes $/ \mathrm{cm}^{2}$ (10 psi). Assuming a low value in this range, a rather steep increase in static bearing strength with penetration and/or a high dynamic factor would be required to reproduce the Surveyor 1 results. On the other hand, a high top surface bearing strength (within the above range) would be associated with a small increase in static strength versus penetration and/or a material with a low dynamic effect. Either behavior is conceivable in a homogeneous material, as well as in a layered material. In a homogeneous material, the bearing strength changes versus penetration are continuous; in a layered material, step function changes occur.

To be satisfactory, an evaluation of lunar surface conditions and events during landing must be based on a reasonable comparison between the results of the computer simulations and the observance of the Surveyor 1 landing performance. However, because of the limited amount of available data and the difficulty in determining the footpad penetration accurately, the dynamic analysis may result in a number of different, but adequate, solutions; i.e., it will not necessarily produce conclusive evidence as to the nature of the lunar surface.

Preliminary results of these investigations show that the rigid surface landing agrees well with Surveyor 1 data with respect to pulse shape, elapsed time between first and second impact, and reimpact pulse shape (Figure 5). The time to build up to the peak shock absorber forces was essentially the same for Surveyor 1 and the rigid surface landing simulation. For the hard-surface simulations, however, the peak forces are 10 and $15 \%$ too high, and the duration of the first impact pulse is slightly too short. These discrepancies seem to be due primarily to the observed penetration into the lunar material.

To date, some soft surface simulations have

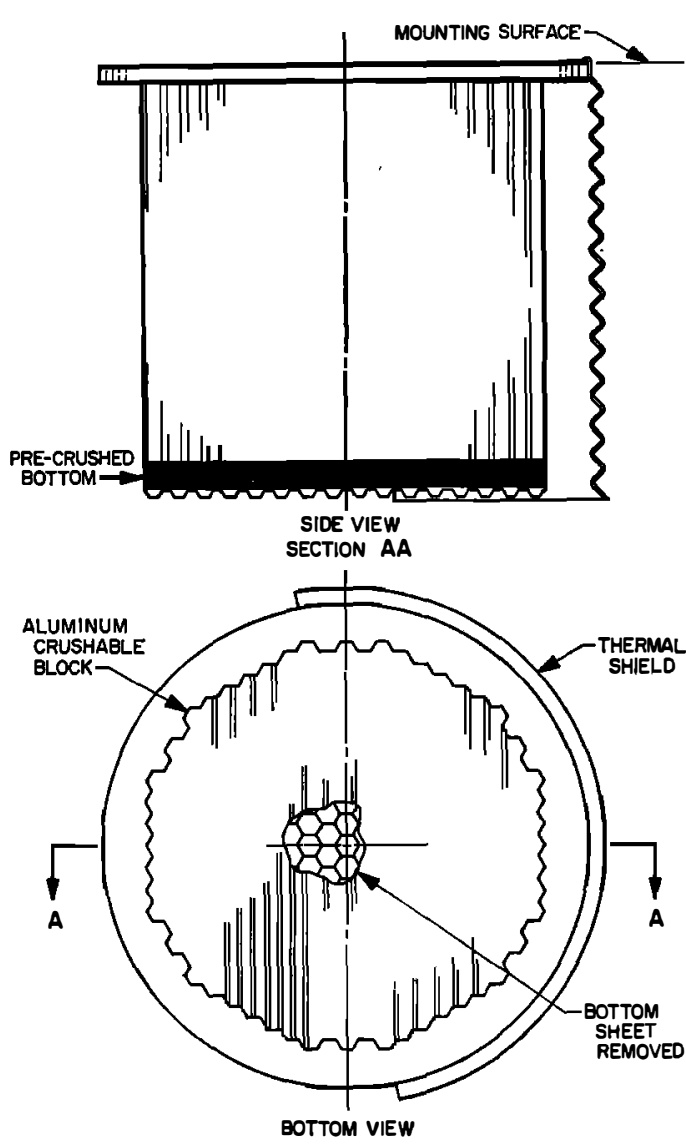

Fig. 14. Two views of crushable block assembly 3 including thermal shield, side view and bottom view.

been performed that show correlation with the shock absorber force time histories through initial and secondary impact. Also, penetrations of footpads and blocks within the limits established by the television picture analysis have been duplicated by soils that have a bearing strength of $3.5 \times 10^{5}$ dynes $/ \mathrm{cm}^{2}(5 \mathrm{psi})$ in the top layer and a density of 1.2 to $1.5 \mathrm{~g} / \mathrm{cm}^{8}$ (2.3 to 3.0 slugs/ $\mathrm{ft}^{\mathrm{a}}$ ). Further investigations are required, however, to extend and confirm these values and to establish limiting relationships between penetration and surface mechanical properties.

Within the limitations of the available data from Surveyor 1, investigations are continuing as to which of the soil behavior possibilities did exist during the Surveyor 1 landing.

The hard-surface analysis indicates that a landing under the Surveyor 1 conditions should have resulted in very little, if any, footpad 


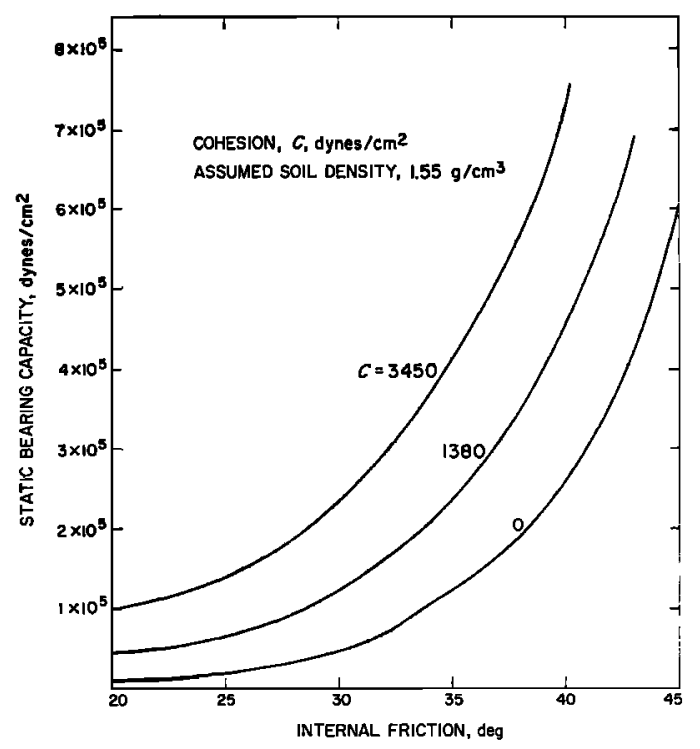

Fig. 15. Possible static bearing capacity of a 30.5 -cm- (1 ft) diameter footing on moon.

crushing, even on an absolutely rigid surface. It is not possible to establish from the television pictures whether or not any crushing took place.

\section{INTERPRETATIONS}

The appearance of the disturbed lunar surface material near the footpads and the rim of the impact depression suggest that the surface is a granular soil-like medium with fine grain size below the resolving capability of the television system. On disruption by the impact, some fine-grained material was thrown out in a spray, possibly from an original surface layer, and the underlying material was broken up to some extent. It appears that the material displaced by the footpads was both thrown and pushed out.

The behavior of the material is consistent with its possession of a distinct, but small, amount of cohesion; because it seems to be somewhat compressible, its manner of deformation appears to be qualitatively similar to the deformation that might be exhibited by a terrestrial damp fine-grained soil.

The appearance of the lunar surface and the nature and depths of the depressions formed during landing are very similar at footpads 2 and 3 , so that, at least to the scale of Surveyor, the material properties seem to be horizontally homogeneous.
There is an uncertainty in the vertical homogeneity of the lunar surface at the Surveyor 1 landing site. Landing dynamic simulations, to date, are unable to differentiate between a hard surface (static bearing capacity greater than $6.9 \times 10^{5}$ dynes $/ \mathrm{cm}^{2}$, or $10 \mathrm{psi}$ ) overlain by a weaker material to a depth of 2.5 to $7.5 \mathrm{~cm}$ (1 to 3 in.), a vertically homogeneous material, or some intermediate material. However, observations of some of the indigenous craters tend to substantiate the vertical homogeneity concept.

The lunar surface did create a maximum dynamic resistance of 4.2 to $6.9 \times 10^{5}$ dynes $/ \mathrm{cm}^{2}$ (6 to $10 \mathrm{psi}$ ) when Surveyor 1 landed. The static bearing capacity and other soil properties that would produce such a dynamic effect have not been conclusively determined.

A number of materials that have a wide range of properties can develop a specific static bearing capacity. By assuming a static bearing capability of $3.5 \times 10^{5}$ dynes $/ \mathrm{cm}^{2}$ (5 psi), one possibility is a soil with a cohesion in the range of 1.3 to $4 \times 10^{3}$ dynes $/ \mathrm{cm}^{2}$ (0.02 to $\left.0.05 \mathrm{psi}\right)$ and a friction angle between $30^{\circ}$ and $40^{\circ}$, at a density typical of terrestrial soil $\left(1.5 \mathrm{~g} / \mathrm{cm}^{2}\right.$ or 3 slugs/ft $\mathrm{ft}^{\mathrm{a}}$, Figure 15).

In the absence of observable spacecraft settling or physical change of the lunar surface material between the initial and the second lunar day, television pictures indicate that the lunar material is reasonably stable with respect to the time and temperature changes during that interval.

Acknowledgments. We extend our appreciation to John Garba, JPL, who contributed significantly to the landing dynamic simulation studies, and to Robert Spencer and Don Schofield for studies and interpretations of television pictures with respect to spacecraft interactions with the lunar surface.

\section{REFerences}

Deitrick, R. E., and R. H. Jones, Touchdown dynamics study for lunar landing phase of Surveyor Project, NASA Rept. CR62080, 1963. Sperling, F., and J. Garba, Surveyor 1 landing dynamics, Jet Propulsion Lab. Tech. Rept. $92-$ 1085, Pasadena, Calif., 1966.

Surveyor 1 mission report, 1, Mission description and performance, Jet Propulsion Lab. Tech. Rept. 32-1023, Pasadena, Calif., August 31, 1966.

(Received November 15, 1966.) 


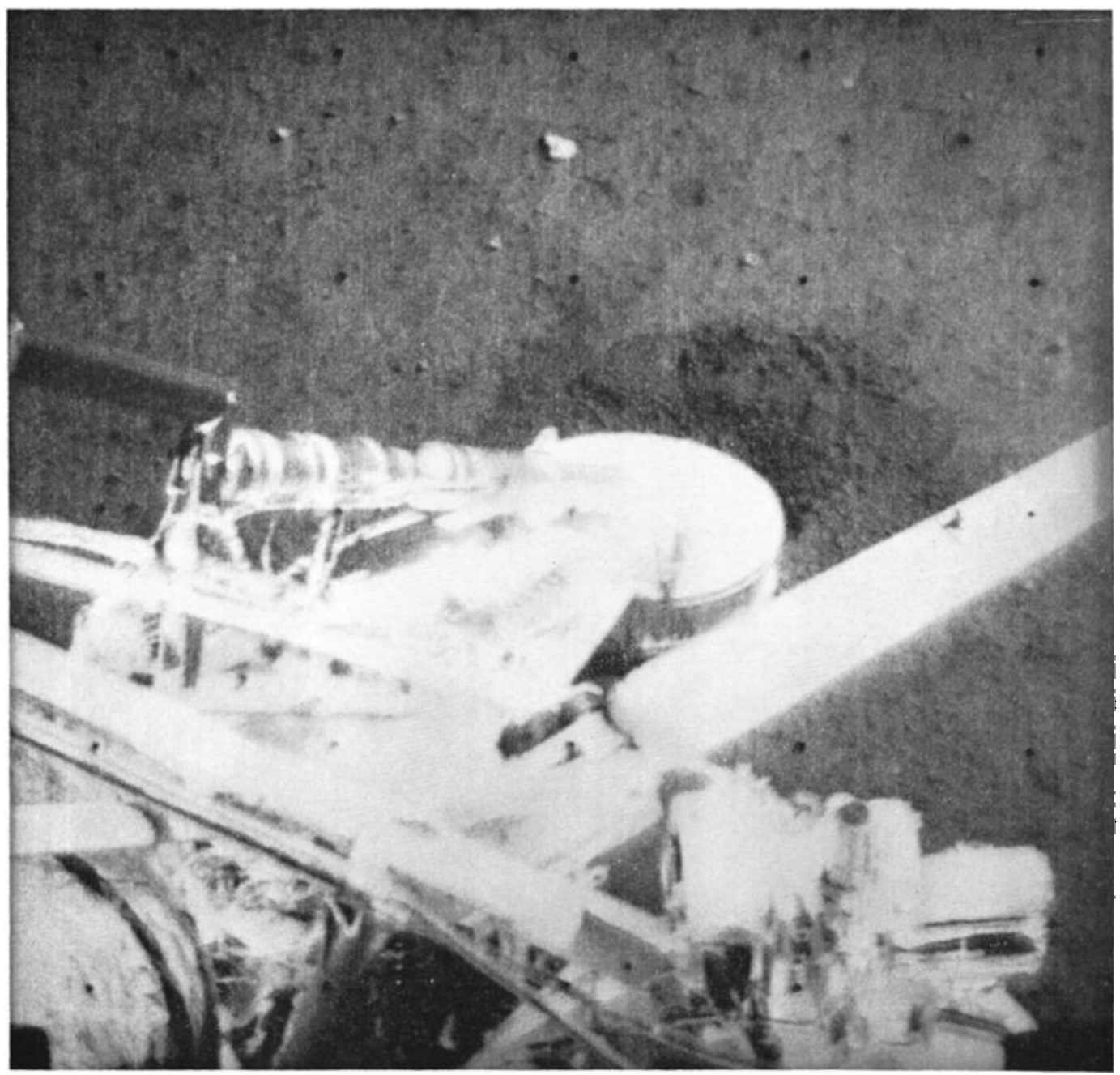

Fig. 6. Christensen et al. Wide-angle picture of footpad 3. Note similarity of throwout material to material shown in Figure 7. 


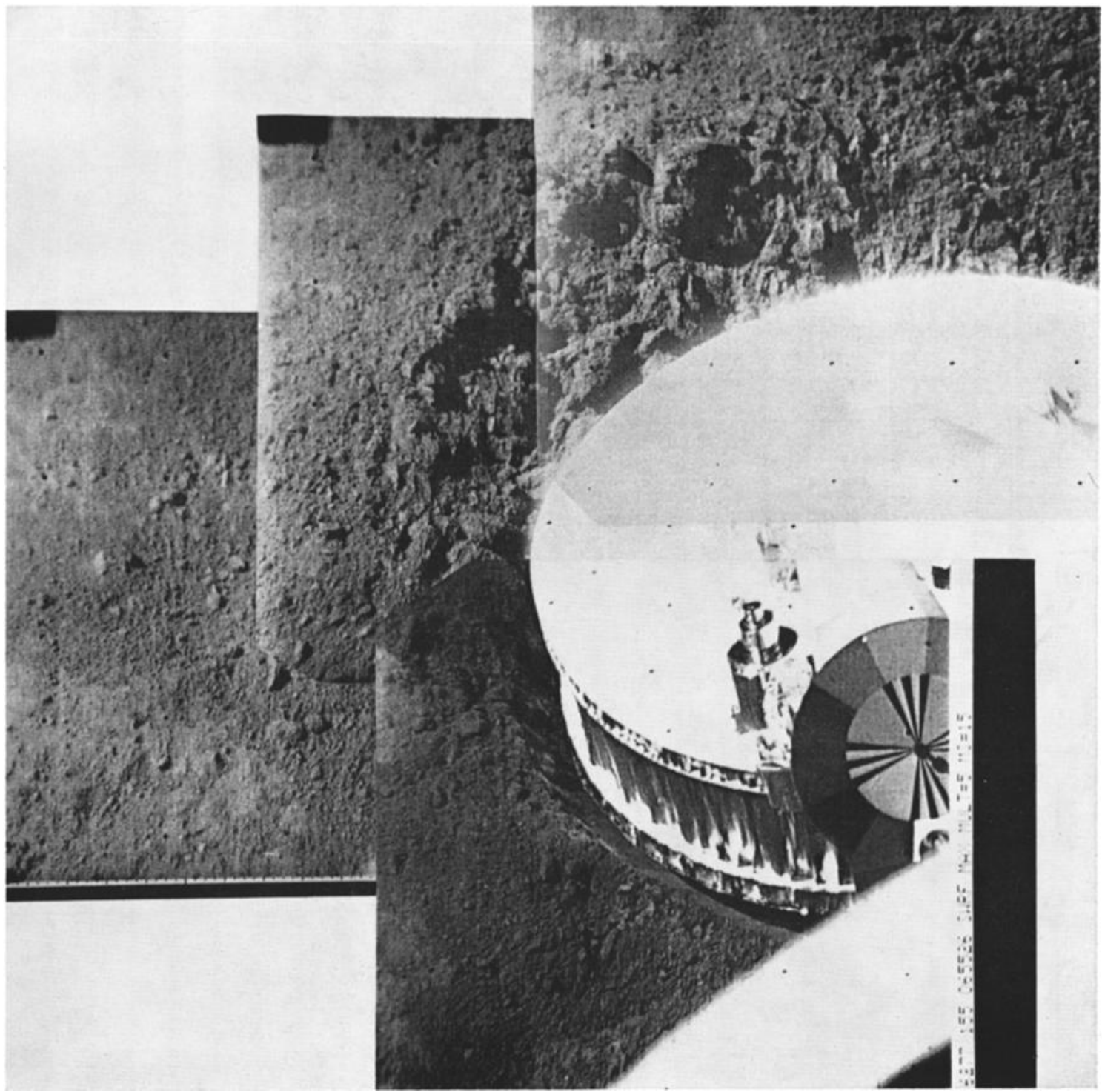

Fig. 7. Christensen et al. Mosaic of computer-processed narrow-angle pictures of footpad 2 area taken on June 4,1966 . Sun angle is $54^{\circ}$. 


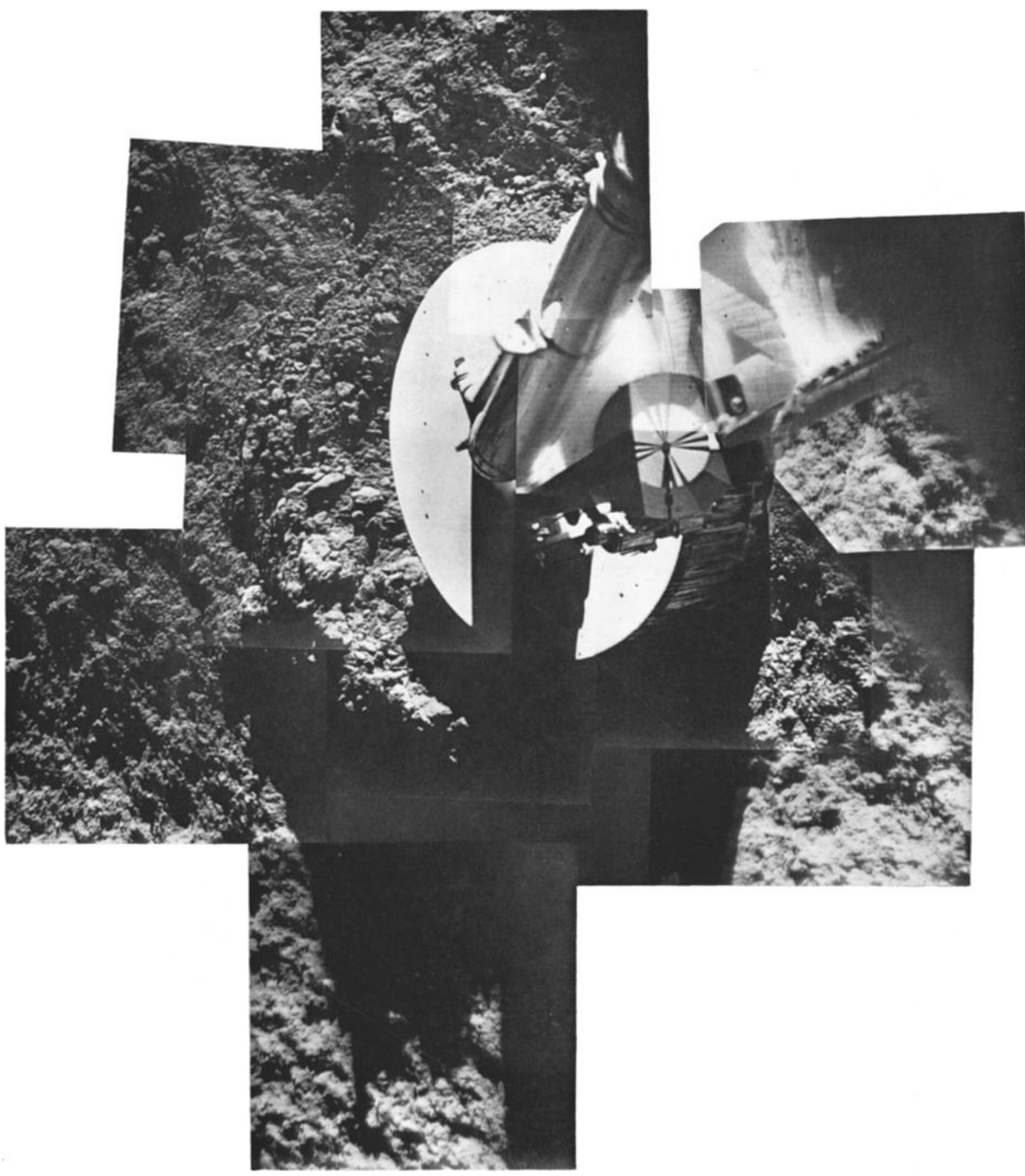

Fig. 8. Christensen et al. Mosaic of computer-processed narrow-angle pictures of footpad 2 area taken on June 13,1966 . Sun angle is $10^{\circ}$. Note that four frames are not computerprocessed. 


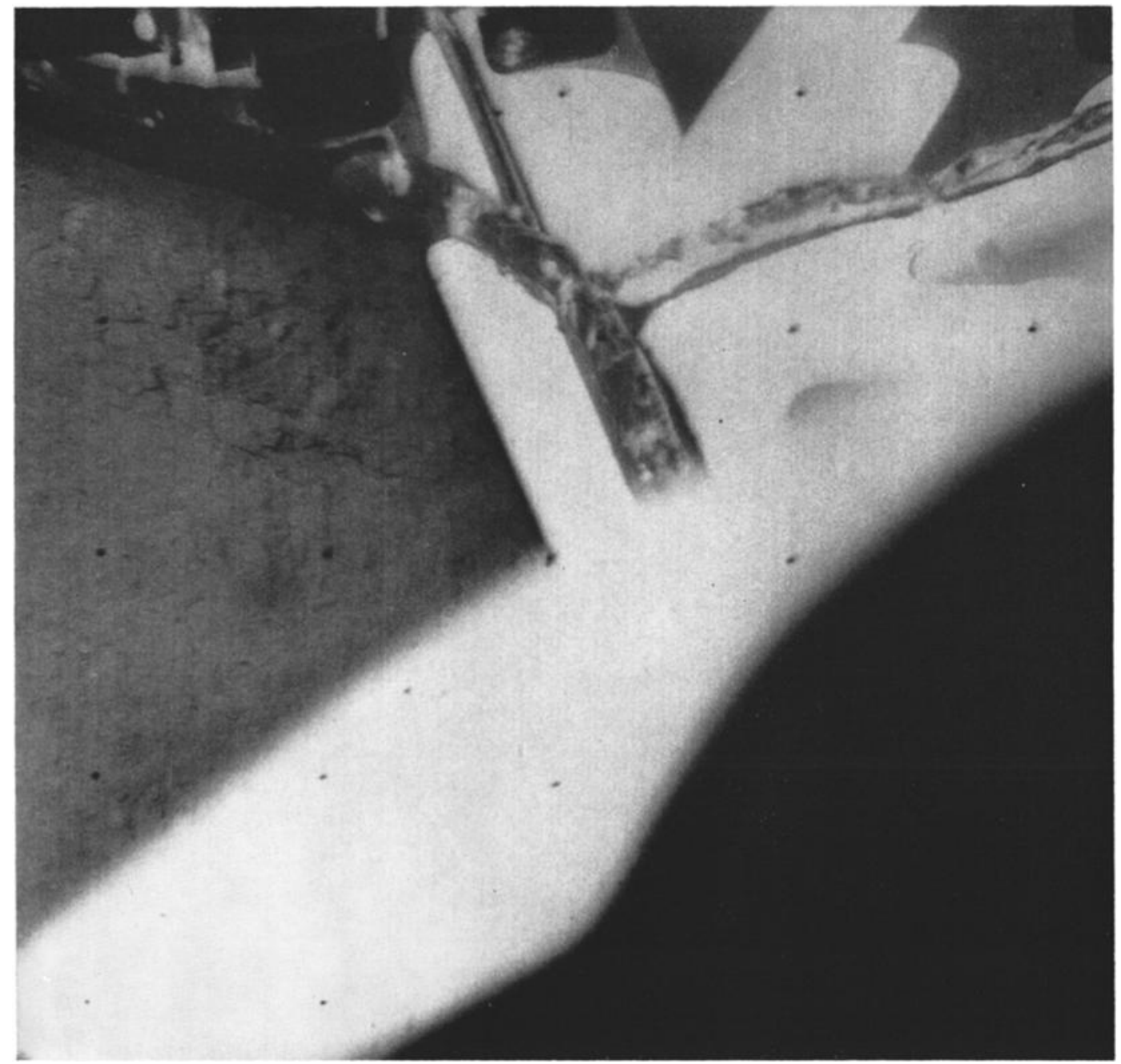

Fig. 9. Christensen et al. Narrow-angle picture of disturbed lunar surface material near footpad 2. Disturbed lunar material is in the approximate area in which the exhaust of the attitude control jet impinged on the surface. 


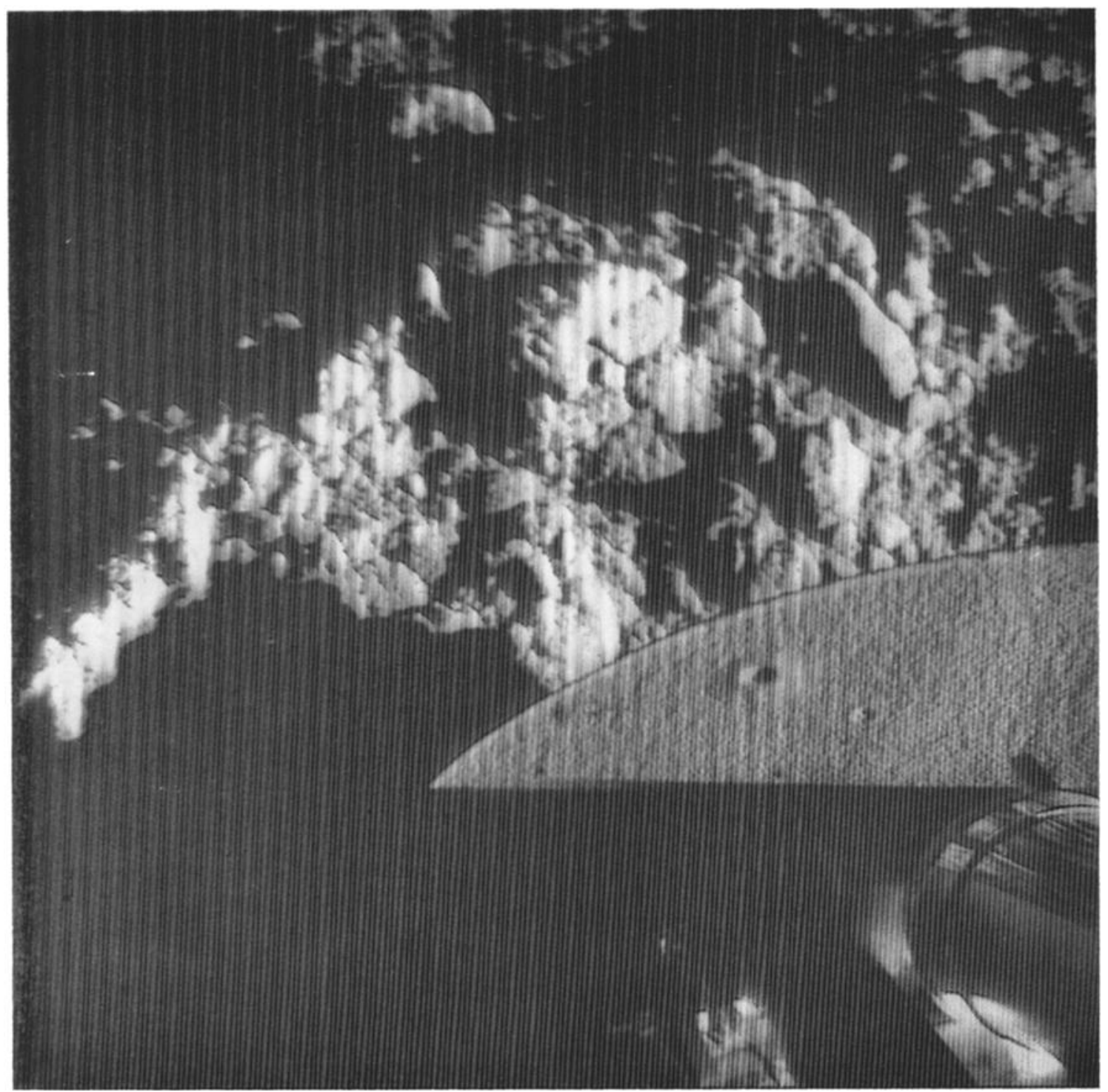

Fig. 10. Christensen et al. Narrow-angle picture of footpad 2. Sun angle is $6^{\circ}$ above horizon; texture on pad top is unexplained. 


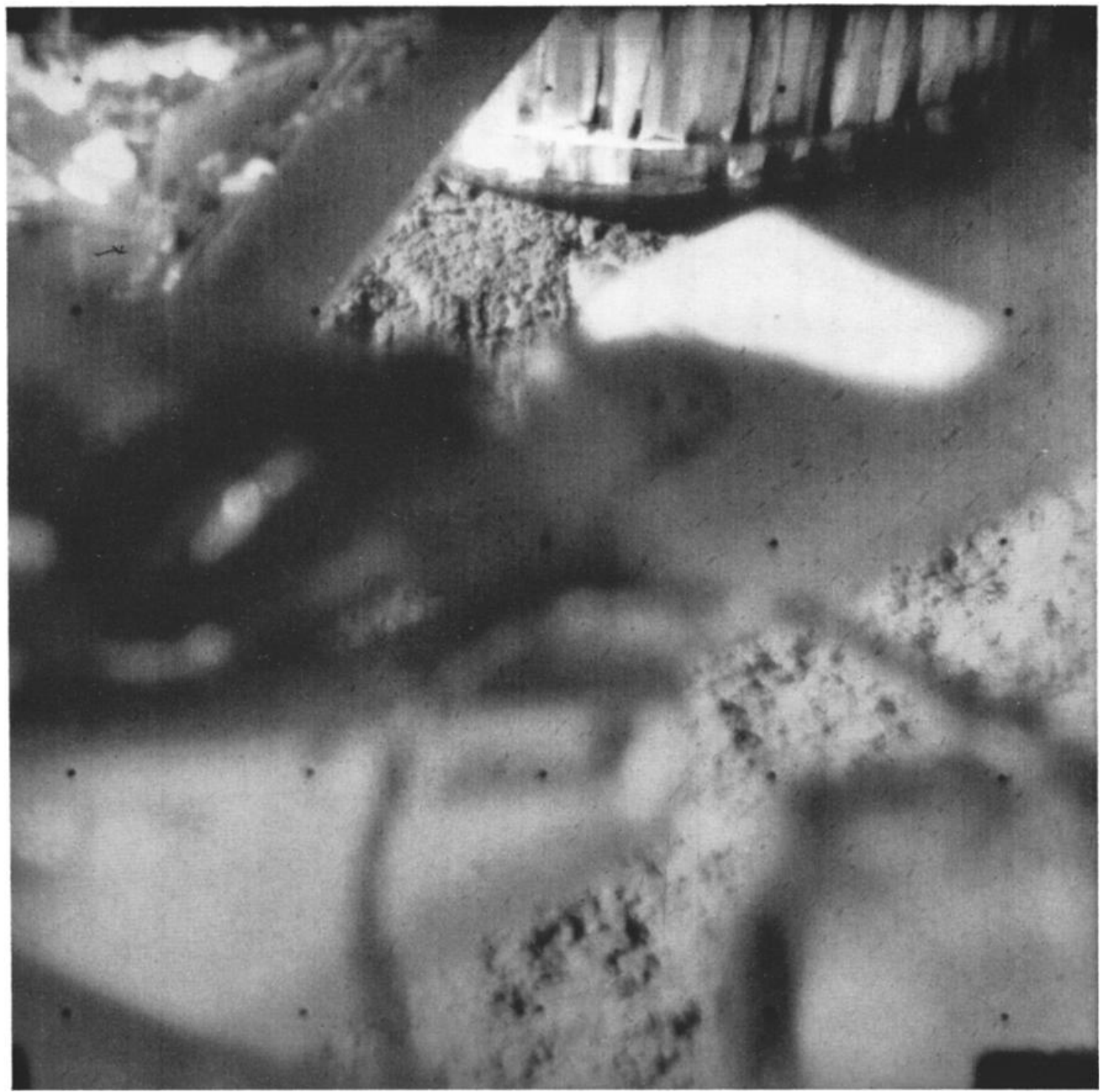

Fig. 11. Christensen et al. Narrow-angle picture of footpad 3. Sun angle is $25^{\circ}$; camera angle from which this picture was taken enabled the surface in foreground of footpad to be seen. 


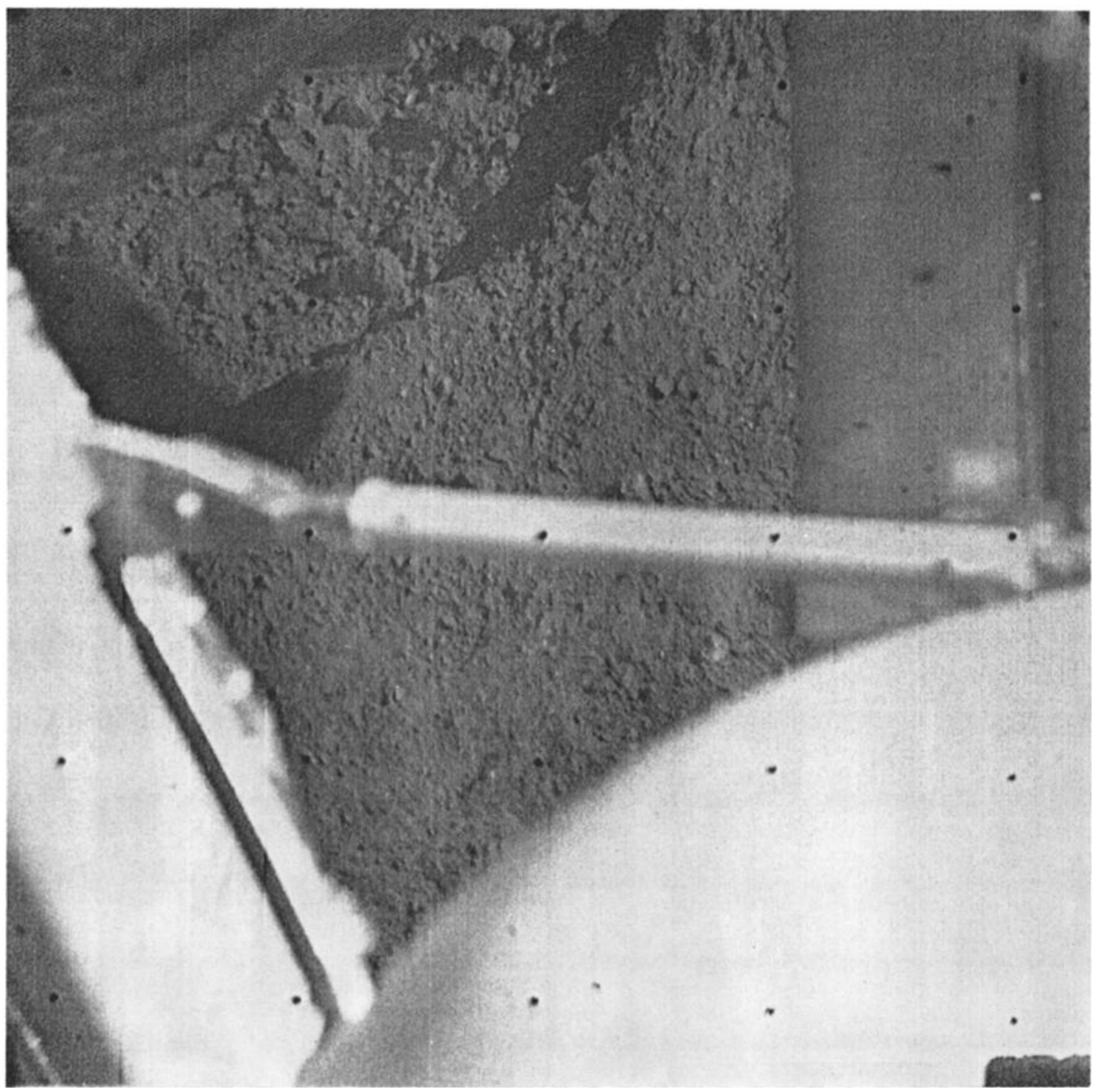

Fig. 12. Christensen et al. Computer-processed picture of surface depression made by crushable block assembly 3 . Note the lunar surface depression in upper left-hand corner; part of the propellant tank obscures the imprint in the extreme left-hand corner. Sun angle is $41^{\circ}$ and from the right of the picture. 


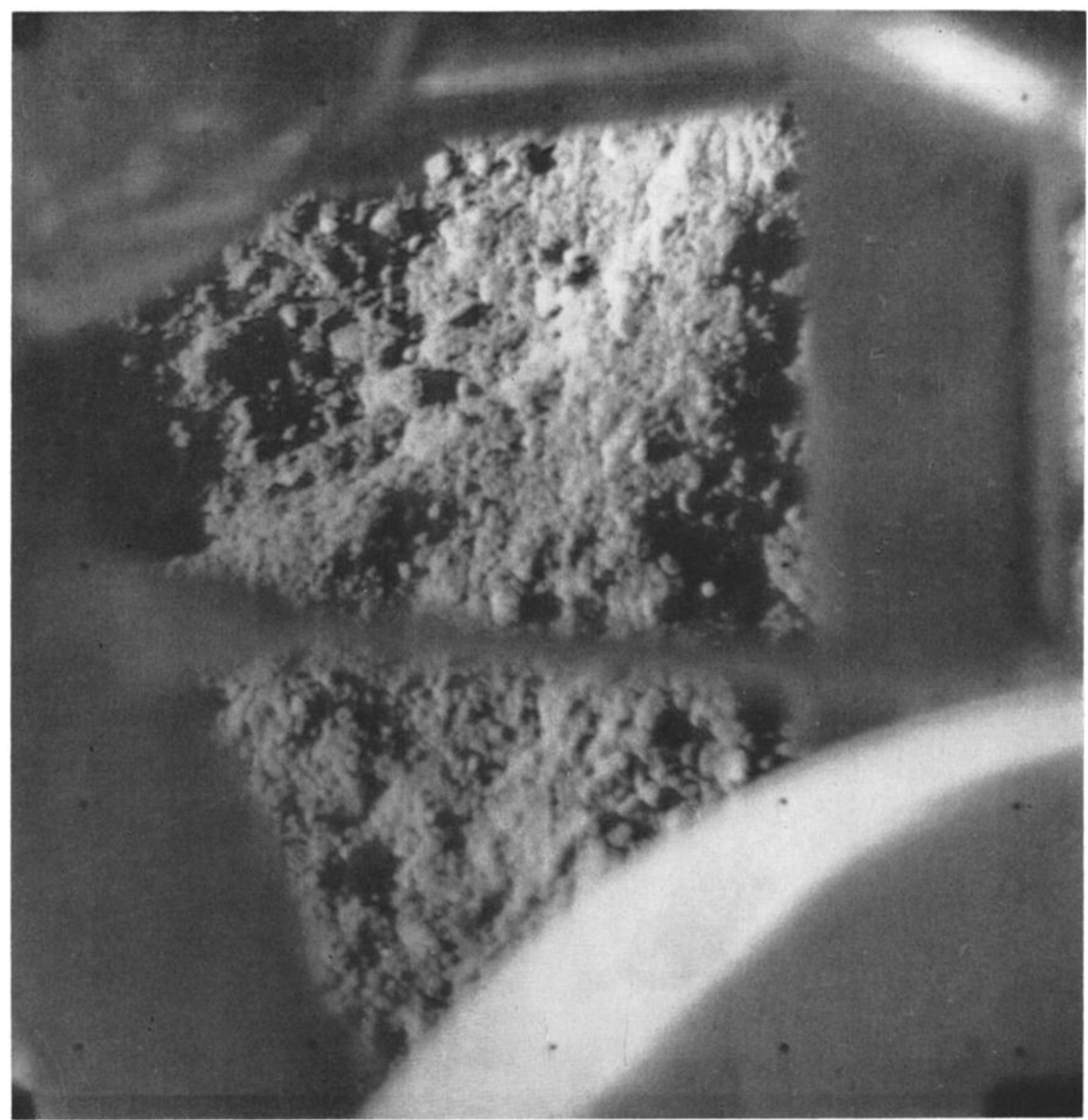

Fig. 13. Christensen et al. Block assembly 3 imprint taken late on the second lunar day. Sun angle is $22^{\circ}$ and from the left of the picture. No noticeable change in the disturbed material has been observed during a time period greater than 5 weeks. 